\title{
To screen or not to screen, what do the Pacific Island athletes teach us?
}

Aro, Aapo L.

2019-03-01

Aro , A L 2019 , ' To screen or not to screen, what do the Pacific Island athletes teach us? ' , International Journal of Cardiology , vol. 278 , pp. 285-286 . https://doi.org/10.1016/j.ijcard.2018.12.011

http://hdl.handle.net/10138/311290

https://doi.org/10.1016/j.ijcard.2018.12.011

unspecified

publishedVersion

Downloaded from Helda, University of Helsinki institutional repository.

This is an electronic reprint of the original article.

This reprint may differ from the original in pagination and typographic detail.

Please cite the original version. 


\title{
Editorial
}

\section{To screen or not to screen, what do the Pacific Island athletes teach us?}

\author{
Aapo L. Aro * \\ Heart and Lung Center, Helsinki University Hospital, Helsinki, Finland
}

\section{A R T I C L E I N F O}

Article history:

Received 2 December 2018

Accepted 3 December 2018

Available online 5 December 2018

It is well established, that physical activity confers substantial health benefits and prolongs life [1]. Paradoxically, however, intensive exercise may also act as a trigger for life-threatening ventricular arrhythmias in case of an underlying cardiac disease [2], occasionally leading to sudden death of a young and apparently healthy person, a catastrophic event with far-reaching implications for families and communities involved.

To prevent these early sports-related deaths, some countries are implementing preparticipation evaluation of trained competitive athletes, which aims at identifying cardiovascular diseases capable of causing cardiac arrest in the athletic field. While there is broad agreement that early detection of these cardiac disorders is an important objective in order to prevent sudden cardiac death (SCD) [3], there has been discussion on appropriate methods, especially if family/personal history and physical examination alone is sufficient, or should it be complemented with a 12-lead ECG. Sensitivity of patient history and physical examination in detecting cardiac disorders with elevated risk of SCD is relatively low, around 20\%, but addition of an ECG to the screening increases the detection, as about $60 \%$ of disorders associated with cardiac arrest in young individuals cause ECG abnormalities [4]. Although the use of modern ECG interpretation standards is likely to improve ECG's accuracy [5], the substantial number of false-positive findings among athletes leading to further investigations has prompted concerns regarding the costeffectiveness of universal ECG screening [6]. On the other hand, sensitivity of screening to detect subclinical cardiomyopathies is still suboptimal with some false-negative results, as demonstrated in a recent study among adolescent soccer players, in which most athletes who experienced SCD during the follow-up didn't have detectable abnormalities in the comprehensive screening [7].

\footnotetext{
DOI of original article: https://doi.org/10.1016/j.ijcard.2018.11.012

* Division of Cardiology, Heart and Lung Center, Helsinki University Hospital, Haartmaninkatu 4, PL340, 00029 HUS Helsinki, Finland.

E-mail address: aapo.aro@helsinki.fi.
}

Nearly all data on cardiovascular screening and incidence of SCD in young athletes have come from Europe or the United States, so the study by Chatard et al. [8] on preparticipation cardiovascular evaluation among Pacific Island athletes published in this issue of the Journal is a welcomed addition to the rapidly growing literature on this somewhat emotional and controversial subject. The authors should be commended for conducting a study in this sparsely populated area spanning thousands of kilometers, although this lead to some difficulties in investigating the abnormal findings further, potentially affecting the results. Among $>2200$ young athletes evaluated, $15 \%$ had abnormal family or personal history, or cardiovascular findings in the clinical examination. Isolated abnormal ECG findings were present in 1\%. Overall, 3.9\% of athletes were found to have cardiovascular abnormalities, and $0.8 \%$ had cardiac pathology carrying a potential risk of SCD, one-third of which were detected only by an abnormal ECG. This prevalence of significant cardiac disorders among athletes is somewhat greater than $0.3-0.4 \%$ reported previously [4,7], reflecting some regional characteristics such as the high prevalence of rheumatic heart disease.

In the study, three SCDs occurred among the screened athletes during the follow-up, with an annual incidence of 1:2500. This magnitude of SCD risk is significantly higher compared to most previous reports, although without screening and exclusion of athletes at risk from competitive sports, the number of deaths could have been even higher. The high incidence of SCD may be partly a chance finding given the relatively small population studied, but it may also be related to the ethnic profile and background of athletes in this geographically distinct area. In the literature, estimates of the incidence of cardiac arrest among athletes has varied widely depending on the definition (whether survivors of cardiac arrest are included or not), methodology and athlete population studied, with most estimates falling between 1:50,000 and 1:80,000 athlete years [4,9]. However, some subgroups such as men, black athletes and basketball players, appear to be at significantly higher risk, with risk estimates closer to this report from the Pacific Islands [4]. Universal athlete screening recommendations with or without ECG fail to acknowledge these large regional differences in the athlete risk profile and prevalence of cardiovascular disorders, so this study highlights the need to understand local circumstances, including the prevalence of cardiovascular disease, incidence of cardiac arrest and resources to spend on screening, when tailoring a preparticipation evaluation program for specific sports and regions.

The study by Chatard et al. also hints to a particular quandary in screening efforts limited to athletes. Given the relatively large number of cardiovascular findings in this Pacific Island population, there is a potential ethical dilemma in confining the preventive and screening 
efforts of potentially lethal cardiac disorders only to those who choose to engage in competitive sports, a segment of the population likely to exhibit healthier lifestyle than the rest. In a recent report from the Oregon Sudden Unexpected Death Study, only $14 \%$ of sudden cardiac arrests in the young were associated with sports. In fact, the majority of cardiac arrests even among the young struck those with traditional cardiovascular risk factors. Survival from sports related cardiac arrest was also significantly better compared to cardiac arrest in non-sports settings [10]. Thus, SCD prevention efforts should not be confined only to athletes, but to all subgroups at high risk, such as relatives of sudden cardiac arrest victims and those with familial cardiac disease, cardiac symptoms or cardiovascular risk factors. To improve SCD risk stratification among the young, novel strategies, tools and risk markers are needed to better recognize individuals with an underlying, potentially life-threatening cardiac disease, irrespective whether they are competitive athletes or not.

\section{Funding}

This work was supported by the Finnish Medical Foundation and the Sigrid Juselius Foundation.

\section{Conflict of interest}

The authors report no relationships that could be construed as a conflict of interest.

\section{References}

[1] D.C. Lee, R.R. Pate, C.J. Lavie, X. Sui, T.S. Church, S.N. Blair, Leisure-time running reduces all-cause and cardiovascular mortality risk, J. Am. Coll. Cardiol. 64 (2014) $472-481$.

[2] D. Corrado, C. Basso, G. Rizzoli, M. Schiavon, G. Thiene, Does sports activity enhance the risk of sudden death in adolescents and young adults? J. Am. Coll. Cardiol. 42 (2003) 1959-1963.

[3] A.L. Aro, S.S. Chugh, Prevention of sudden cardiac death in children and young adults, Prog. Pediatr. Cardiol. 45 (2017) 37-42.

[4] J.A. Drezner, F.G. O'Connor, K.G. Harmon, et al., AMSSM position statement on cardiovascular preparticipation screening in athletes: current evidence, knowledge gaps, recommendations and future directions, Br. J. Sports Med. 51 (2017) 153-167.

[5] S. Sharma, J.A. Drezner, A. Baggish, et al., International recommendations for electrocardiographic interpretation in athletes, J. Am. Coll. Cardiol. 69 (2017) 1057-1075.

[6] B.J. Maron, B.D. Levine, R.L. Washington, et al., Eligibility and disqualification recommendations for competitive athletes with cardiovascular abnormalities: task force 2: preparticipation screening for cardiovascular disease in competitive athletes: a scientific statement from the American Heart Association and American College of Cardiology, Circulation 132 (2015) e267-e272.

[7] A. Malhotra, H. Dhutia, G. Finocchiaro, et al., Outcomes of cardiac screening in adolescent soccer players, N. Engl. J. Med. 379 (2018) 524-534.

[8] J. Chatard, F. Espinosa, R. Donnadieu, Pre-participation cardiovascular evaluation in Pacific Island athletes, Int. J. Cardiol. 278 (2019) 273-279.

[9] C.H. Landry, K.S. Allan, K.A. Connelly, et al., Sudden cardiac arrest during participation in competitive sports, N. Engl. J. Med. 377 (2017) 1943-1953.

[10] R. Jayaraman, K. Reinier, S. Nair, et al., Risk factors of sudden cardiac death in the young: multiple-year community-wide assessment, Circulation 137 (2018) 1561-1570. 